\title{
RELIABILITY OF VARIABILITY SOURCE DETECTION IN SHAININ'S COMPONENT SEARCH PROCEDURE
}

doi: 10.2478/cqpi-2019-0048

Date of submission of the article to the Editor: 07/04/2019

Date of acceptance of the article by the Editor: 01/06/2019

Jacek Pietraszek ${ }^{1}$ - orcid id: 0000-0003-2851-1606

Renata Dwornicka ${ }^{1}$ - orcid id: 0000-0002-2979-1614

Andrii Goroshko ${ }^{2}$ - orcid id: 0000-0002-1386-2326

${ }^{1}$ Cracow University of Technology, Kraków, Poland

${ }^{2}$ Khmelnitskyi National University, Khmelnitskyi, Ukraine

Abstract: Shainin's component search procedure uses variability source detection based on specific median test. This approach has only two triple subsets and the certainty of inference can be weak for this reason. This paper checks this approach by series of numerical simulations.

Keywords: Shainin, Red- $X^{\circledR}$, Component Search ${ }^{\circledR}$, bootstrap

\section{INTRODUCTION}

General overview. Red- $X^{\circledR}$ concept is a general scheme of procedures being partly algorithmic, partly heuristic, which should lead to stabilization of production process or product behavior i.e. to obtain a reduction in process variability. The name "Red-X" was created by American engineer Dorian Shainin employed in Grumman Aircraft in the sixties of the twentieth century. This abbreviation was to indicate the main cause of process instability, the finding of which is the goal of corrective actions. The scheme of corrective activities was created evolutionarily from the beginning of the fifties, expanded by further components. In the late nineties it was formalized (Bhote, 2000). The most famous achievement of Shainin at Grumman Aircraft was the effective management of the quality system in the construction of the LEM lunar lander in the APOLLO project, however Shainin introduced very effective quality system into Motorola and General Motors.

Component Search ${ }^{\circledR}$ overview. This part of Shainin's scheme consists of two blocks separated by an important decision. In the first block, the variability introduced by components is compared to variability introduced by assembly process. If component variability dominates then the second block is started where variabilities of components are compared mutually. Otherwise, the suggestion of assembly process stabilization is expressed.

The key assumption in this procedure is a possibility to decompose tested product into separate components and then assembly them again. The first step focuses on selection of the worst (later called WoW ${ }^{\circledR}-$ Worst of Worsts) and the best (later called 
$\mathrm{BoB}^{\circledR}$ - Best of Bests) copy of the product. Next, the quantitative outcome (previously selected variable whose stabilization is the aim of the procedure) of both product copies is recorded into two separate bins of data. Both product copies are decomposed and assembled again - outcomes are recorded second time. Decomposition and assembling is conducted again - outcomes are recorded third time. In this moment, two bins of WoW and BoB contain three data each.

Shainin assumed that further calculation will be conducted based on median and range, not mean and standard deviation. He argued that median and range create more stable and robust decision background. So the medians and ranges of BoB:

$$
\begin{gathered}
m_{\mathrm{BoB}}=\operatorname{median}\left(\mathrm{BoB}_{1}, \mathrm{BoB}_{2}, \mathrm{BoB}_{3}\right) \\
d_{\mathrm{B} \circ \mathrm{B}}=\max \left(\mathrm{BoB}_{1}, \mathrm{BoB}_{2}, \mathrm{BoB}_{3}\right)-\min \left(\mathrm{BoB}_{1}, \mathrm{BoB}_{2}, \mathrm{BoB}_{3}\right)
\end{gathered}
$$

and WoW are calculated:

$$
\begin{aligned}
& \text { mwow }=\text { median }\left(\mathrm{WoW}_{1}, \mathrm{WoW}_{2}, \mathrm{WoW}_{3}\right) \\
& \mathrm{d}_{\mathrm{Wow}}=\max \left(\mathrm{WoW}_{1}, \mathrm{WoW}_{2}, \mathrm{WoW}_{3}\right)-\min \left(\mathrm{WoW}_{1}, \mathrm{WoW}_{2}, \mathrm{WoW}_{3}\right)
\end{aligned}
$$

Next, the difference between medians $D$ and average range $d$ is calculated:

$$
\begin{gathered}
D=\left|m_{B o B}-m_{W o w}\right| \\
d=\left(d_{B o B}+d_{W o w}\right) / 2
\end{gathered}
$$

Finally, the ratio $D / d$ is evaluated and it is a base for decision:

- if $D / d>1.25$ then search the variability source in the set of components

- if $D / d<1.25$ then stabilize the assembly process first i.e. assembly process variability dominates over the variability introduced by components.

Research question. Shainin vaguely argued the selection of the "magic number" 1.25. Therefore, the question arises what is the level of false decisions based on the above scheme, especially that the sample size is small.

\section{METHODS}

The numerical simulation based on Monte Carlo was selected as a tool.

Let assume that two normal distributions $\mathrm{N}(0,1)$ and $\mathrm{N}(\mathrm{w}, 1)$ are sources of samples. The parameter $\mathrm{w}$ is related to difference between WoW and BoB, however it is studentized by the assembly process variability i.e. standard deviation being equal 1 . Let $B$ is a set of three elements sampled from $N(w, 1)$ while $W$ is a set of three elements sampled from $N(0,1)$. Let $R$ is a decisive ratio $D / d$ calculated according to equations (1$6)$.

What is the percentage of $R$ value in the function of the "w" parameter that are greater than 1.25 ?

Due to the simulation nature, the $R(w)$ functions will create the band of confidence in the plot.

The range of tested " $w$ " values was set from 0 to 4 . The number of iterations for each value of " $w$ " was set to 10000 (it is convenient value to select the confidence interval 0.95). 


\section{RESULTS}

The Figure 1 shows the percentage (i.e. empirical probability) of decisions claiming domination of variability from assembly process over the variability from components.

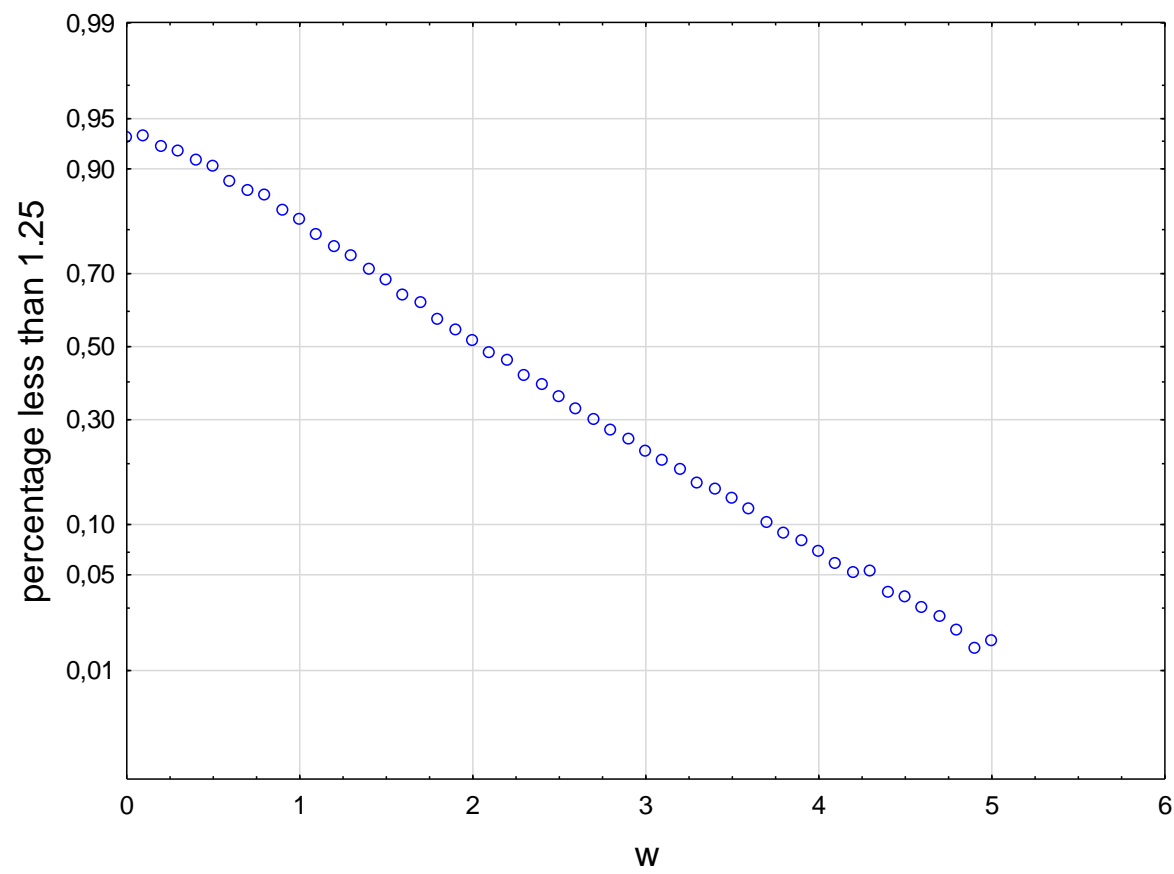

Fig. 1. Percentage of decisions declining further component search

The Figure 2 shows the dependence of the ratio $\mathrm{R}$ from the parameter $\mathrm{w}$. It reveals that practically all decisions agree to ignore the assembly process variability when the difference between WoW and BoB is 5 times greater than their standard deviation i.e. the variability of the assembly process.

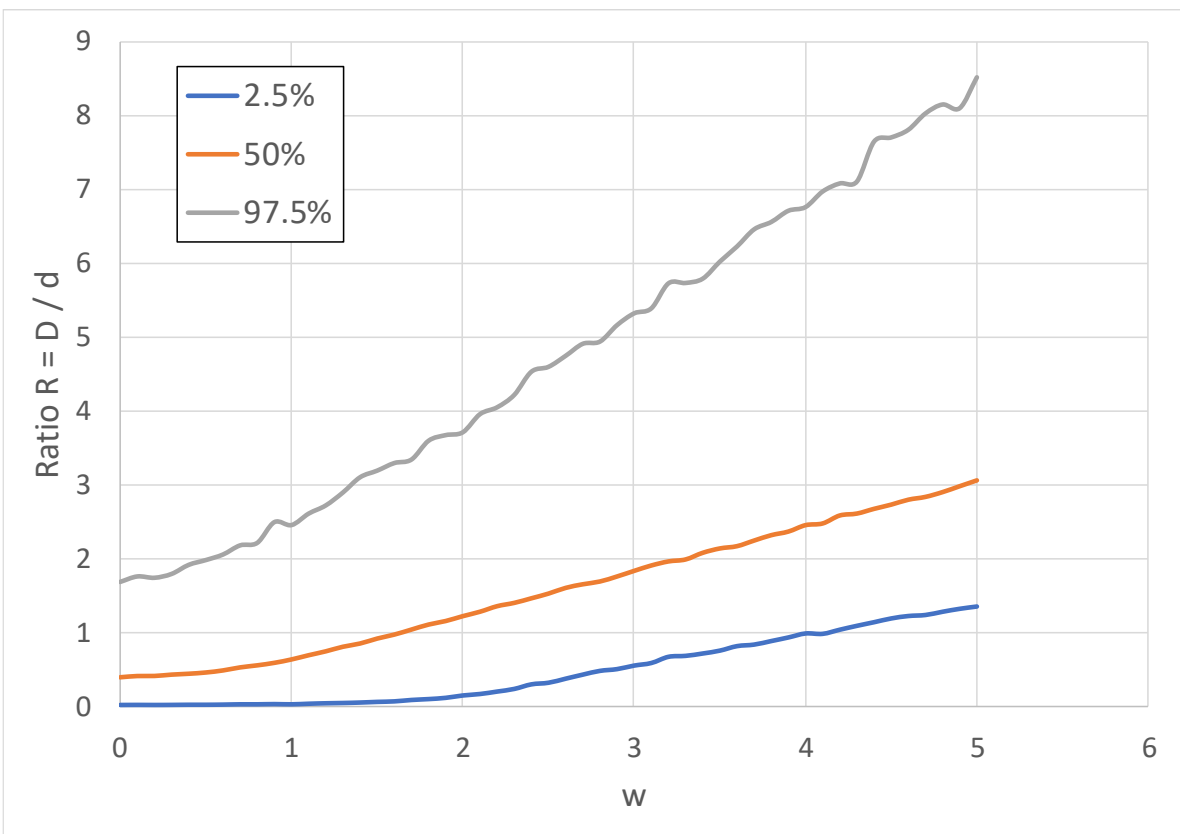

Fig. 2. Bound of confidence for decisive ratio $R$ as a function of parameter $\mathrm{w}$ 
The fluctuations visible in the plot in Fig. 2 are related to the randomness of the numerical simulation.

\section{DISCUSSION}

The percentage of the decision refusing to search for components decreases systematically as the distance - i.e. the parameter " $w$ " - between the two distributions increases. The most serious risk is to start searching for components variability when BoB and WoW are almost the same, and the observed differences between them in results are just artifacts. This risk is estimated as $6 \%$. It is the risk that properly provided Shainin's procedure fails due to the random behavior.

\section{CONCLUSION}

Shainin's procedure is considered simple to use and very effective. It is well received in industry and is very popular. It seems that its pragmatic application in the improvement of production processes is profitable. However, it should be remembered that it is largely heuristic and has a large impact of random factors. It seems reasonable to use it at the initial stage of process stabilization, but the more sophisticated DOE methods should be used at further stages. In particular, it should be very carefully used in scientific research, because it can lead to wrong conclusions.

The results presented in this paper may be interesting for researchers and engineers using complex processes with many weakly controlled factors causing large level of noise in outcome e.g. protective coating for trains (Pasieczynski et al., 2018), welding (Strzelaczak and Dudek, 2018), surface improvement and machining (Lisiecka and Dudek, 2018; Ulewicz and Selejdak, 2018), laser texturization for friction modification (Pliszka et al., 2018; Radek et al., 2018), prototype building from polymers (Pacana and Pacana, 2018), boilers improvement (Orman et al., 2018a; Orman et al., 2018b) or pipe creeping (Osocha, 2018). The partly certain knowledge about sources of instability may be also useful in museum revitalization (Karpisz and Kielbus, 2019) and image analysis (Gadek-Moszczak et al., 2014; Gadek-Moszczak, 2017; Gadek-Moszczak and Matusiewicz, 2017) related to materials science. It also seems that fuzzy approach may more appropriate method to analyze results than strict quantitative comparison e.g. fuzzy assessment of ANOVA results (Pietraszek et al., 2016).

\section{REFERENCES}

Bhote, K., 2000. World Class Quality: Using Design of Experiments to Make It Happen, Amacom, New York.

Gadek-Moszczak, A., 2017. History of stereology. Image Analysis \& Stereology, 36, 151-152. DOI: 10.5566/ias.1867

Gadek-Moszczak, A., Matusiewicz, P., 2017. Polish stereology - a historical review. Image Analysis \& Stereology, 36, 207-221. DOI: 10.5566/ias.1808

Gadek-Moszczak, A., Radek, N., Wronski, S., Tarasiuk, J., 2014. Application the 3D image analysis techniques for assessment the quality of material surface layer before and after laser treatment. Adv. Mat. Res. Switz., 874, 133-138. DOI: 10.4028/www.scientific.net/AMR.874.133

Karpisz, D., Kielbus, A., 2019. The Revitalization of Radar System as a Case of Functional and Information Security Problems. System Safety: Human - Technical Facility - Environment, 1, 692-699. DOI: 10.2478/czoto-2019-0088 
Lisiecka, B., Dudek, A., 2018. The Surface Treatment of Sintered Stainless Steel. Materials Research Proceeding, 5, 148-153. DOI: 10.21741/9781945291814-26

Orman, L.J., Radek, N., Broncek, J., 2018a. Sintered Mesh Layers for the Production of Efficient Phase - Change Heat Exchangers. Materials Research Proceedings, 5, 189-193. DOI: 10.21741/9781945291814-33

Orman, L.J., Radek, N., Kapjor, A., 2018b. Surface Treatment Technologies for Boiling Heat Transfer Augmentation. Materials Research Proceedings, 5, 216-219. DOI: 10.21741/9781945291814-38

Osocha, P., 2018. Calculation of Residual Life for P91 Material Based on Creep Rate and Time to Rupture. Materials Research Proceedings, 5, 177-182. DOI: 10.21741/9781945291814-31

Pacana, J., Pacana, A., 2018. Analysis of Possibilities of Using Polymeric Materials for Testing Prototypes of Harmonic Drive. Materials Research Proceedings, 5, 61-66. DOI: 10.21741/9781945291814-11

Pasieczynski, L., Radek, N., Klonica, M., Kaminski, J., Swiderski, J., 2018. Properties of BO100-AGR Clearcoat Anti-Graffiti Coating Systems used in the Railway Industry. Materials Research Proceedings, 5, 225-230. DOI: 10.21741/9781945291814-40

Pietraszek, J., Kolomycki, M., Szczotok, A., Dwornicka, R., 2016. The fuzzy approach to assessment of ANOVA results. ICCCI 2016: Conf. on Comp. Collective Intell. Springer, 260-268. DOI: 10.1007/978-3-319-45243-2_24

Pliszka, I., Radek, N., Gadek-Moszczak, A., Fabian, P., Paraska, O., 2018. Surface Improvement by WC-Cu Electro-Spark Coatings with Laser Modification. Materials Research Proceedings, 5, 237-242. DOI: 10.21741/9781945291814-42

Radek, N., Pietraszek, J., Antoszewski, B., 2014. The Average Friction Coefficient of Laser Textured Surfaces of Silicon Carbide Identified by RSM Methodology. Adv. Mat. Res.-Switz., 874, 29-34. DOI: 10.4028/www.scientific.net/AMR.874.29

Ulewicz, R., Selejdak, R., 2018. Impact of Laser Machining on the Structure and Properties of Tool Steels. Materials Research Proceeding, 5, 37-40. DOI: DOI: 10.21741/9781945291814-7

Strzelczak, K., Dudek, A., 2018. Characteristics of Multimaterial Joints of Nickel-Based Superalloys. Materials Research Proceedings, 5, 166-171. DOI: 10.21741/9781945291814-29 